\title{
Merleau-Ponty. Le monde sensible et le monde de l'expression. Cours au Collège de France. Notes, 1953. \\ Texte établi et annoté par Emmanuel de Saint Aubert et Stefan Kristensen. Genebra: MetisPresses, 2011
}

\author{
Cristiano Perius (Universidade Estadual de Maringá, Maringá, Paraná, \\ Brasil) \\ cristianoperius@hotmail.com \\ Matheus Hidalgo (Universidade Federal de Sergipe, Aracaju, Sergipe, \\ Brasil) \\ matheushidalgo@gmail.com
}

A publicação de 0 Mundo sensivel e o mundo da expressão, em outubro de 2011, traz a público uma parte do material inédito de Merleau-Ponty, depositado na Biblioteca Nacional de Paris, conhecido apenas por pesquisadores e antigos alunos. A nova publicação, aos cuidados de Emmanuel de Saint Aubert e Stefan Kristensen, vem suprir uma “situação inicial de vazio editorial entre a Fenomenologia da percepção e 0 visível e o invisível", como aponta Saint Aubert, na introdução do volume. A passagem de uma fenomenologia descritiva, no primeiro período, para a ontologia da carne, no segundo, dava a entender um momento de ruptura no projeto do filósofo que deixou atrás de si (sic) "hipóteses interpretativas fortes, por vezes fecundas, mas desprovidas de uma base argumentativa suficiente, falta de matéria textual existente" (p. 7). Ora, é nesse espaço ininterrupto de trabalho que, segundo Saint Aubert, "a exploração dos inéditos, depois de alguns anos, permite progressivamente melhor compreender a evolução deste pensamento, mais contínuo do que se acreditava" (id., ibid.). Mais do que uma amostragem do material inédito de Merleau-Ponty (segundo Saint Aubert, mais de quatro mil páginas!), o livro, que está dividido em dois grandes conjuntos de notas ("notas preparatórias do curso", pp. 45-170, e "notas de trabalho", pp. 171-211), constitui um material da maior importância para que se possa compreender como o tema da expressão desempenha, na 


\section{6}

década de 50, a passagem da vida perceptiva para as especificidades da cultura, da linguagem e da história.

Na forma de curso universitário, o primeiro de Merleau-Ponty no Collège de France, as notas que compõem 0 mundo sensivel e o mundo da expressão vieram a lume durante o primeiro semestre de 1953, imediatamente sucessivo aos cursos na Sorbonne (1949-1952) e à redação de $A$ prosa do mundo, publicada apenas em 1969, por Claude Lefort. A intenção do filósofo, segundo a dupla finalidade do curso, é a de a) "aprofundar a análise do mundo percebido, mostrando que ele já supõe a função expressiva"; e b) "preparar a análise desta função, pela qual o mundo percebido é sublimado: fazer uma teoria concreta do espírito" (p.45, lição 1). A análise do espaço e do tempo é conduzida aos deslocamentos intencionais e expressivos do corpo, revelando uma ligação inseparável entre o campo simbólico e o campo motor. É a motricidade do corpo, no curso de 53, que desperta a vocação expressiva da percepção. Deslocando-se, o corpo projeta, antecipa, imagina, a ponto de exigir uma reforma no conceito de consciência tal como vinha sendo praticado, em sentido estrito, na Fenomenologia da percepção. Consciência encarnada significa, a partir das pesquisas da década de 50, consciência motora, isto é, "consciência cega" e não idêntica a si. Como aponta Saint Aubert, “0 mundo sensível e o mundo da expressão rejeita toda concepção estática e positiva da consciência: uma consciência de um ponto de vista sem ponto de vista - aquela de um 'sobrevôo absoluto' de Raymond Ruyer, meta-espacial e meta-temporal" (p. 14), não pode ser a consciência concreta. Razão pela qual MerleauPonty opõe, ao conceito identitário e monádico de consciência, à "consciência prisioneira de si mesma", um conceito de consciência não idêntica a si mesma, consciência em que ser e significação não coincidem, mas geram trabalho, proximidade e distância, esforço motor e lingüístico. A dialética de ser e não ser idêntica a si mesma, segundo o modelo da proximidade e distância, é conduzida a uma "teoria da percepção como diferença". Bem antes de Derrida e Deleuze, o tema da diferença é invocado no sentido de provocar uma mudança na lógica do pensamento. Segundo Saint Aubert “a lógica perceptiva é estranha à consideração clássica da diferença sobre o fundo da identidade. [Se] a identidade dos termos desenha-se na tensão de suas diferenças, os contornos emergem da usurpação (empiétement) de coisas. Merleau-Ponty sai do quadro epistemológico da definição aristotélica, típica do procedimento retrospectivo da inteligência projetiva: o definido é sempre definido sobre o fundo de..., sobre o fundo da positividade prévia de um gênero, no seio do qual se desenha a diferença específica. A consciência da separação (écart) revela enfim quanto o mito do face a face da consciência e do objeto é uma ilusão retrospectiva: nunca há um objeto, sempre há muitas coisas - mas esta seria a figura e o fundo, com a possibilidade e até mesmo a iminência de sua inversão (renversement)" (p. 19). Merleau-Ponty 
privilegia a dimensionalidade, a reversibilidade e a modulação de uma consciência que não é ela mesma se não integrar o ingrediente negativo (desempenhado pela inconsciência ou pelo esquecimento ativo). Da mesma forma que a fala enreda o silêncio e o não-dito, a consciência é uma modalidade do ser que não é representação de um objeto, mas relevo, nível ou dimensão da existência que apenas avança valendo-se da possibilidade de ser intercâmbio, invasão (empiétement) sobre o mundo das coisas e das outras consciências.

Precisemos melhor o sentido da percepção como teoria da diferença. Na segunda lição do curso 0 Mundo sensivel e o mundo da expressão, há uma passagem que diz: “Isto, em relação a que há um desvio (écart), não está posto, mas subentendido como fundo. 0 desvio ele mesmo não chega a ser definido. (...) [Ele é sentido] então como nível. Sua percepção é impercepção: é quando são destruídos que os sentimos. (...) Portanto, sentido perceptivo = desvio em relação ao nível que não é tema. (...) Expressão ou expressividade = propriedade que tem um fenômeno de revelar, por seu agenciamento interno, um outro que não é e que jamais foi dado atualmente." (pp. 5657, lição 2) A intenção de Merleau-Ponty é mostrar o movimento da consciência em relação ao que ainda não é, nem está dado de forma objetiva. Mas esse é o papel desempenhado pela expressão nesse momento: fazer ouvir o não-dito, mostrar a diferença, sublinhar a distância entre o que estamos acostumados a ver e o (até então) invisível. 0 sentido da expressão aqui invocado não é formal, como no caso de $A$ Dúvida de Cézanne e $A$ linguagem indireta e as vozes do silêncio, que analisam a obra de arte, mas cumpre a função de preparar o terreno, abrir espaço para a diferença, no interior da identidade. $A$ expressão aqui não é falante, não tem forma típica, apoio real ou essência visível. Em outras palavras, não é figura, é fundo. Como aponta Merleau-Ponty, "o sentido perceptivo não é um enunciado, um eu sei que, ele é tácito; não é feito de significações livres, que existem por sua própria conta ou para si - p.ex. um verde colocado num rosto vale como um 'sorriso' (fazemos sorrir uma bochecha, diz Cézanne), como uma palavra colocada numa frase modifica a inflexão afetiva" (pg. 57, lição 2). É este verde acrescentado ao rosto, esta palavra acrescentada à frase, que assinala o desvio, a torção, a diferença, a partir de uma região conhecida de nomes. Merleau-Ponty sublinha a convergência entre a teoria lingüística do signo e a teoria do sentido como diferença. $A$ partir de Saussure sabemos que os signos não têm significado objetivo, mas opositivo, diferencial e negativo. Se a consciência representava a certeza de uma essência, um wesen, confirmado por um enunciado, um eu sei que, uma experiência falante (p. 49 e p. 55, lição 1), então a "consciência perceptiva (como expressão)", nas palavras de Merleau-Ponty, "não é a posição de um enunciado, não carrega significações livres (...), [mas] significações ligadas, não falantes, estruturas. (...) Por isso há sempre alguma 


\section{8}

coisa de inarticulado e subentendido onde houver a consciência." (pp. 50-51, lição 1). 0 fato de não ser positiva, mas ligada ao não-dito, agora, não é prejudicial ou pejorativo, pelo contrário, indica abertura ao novo e a operação do diacrítico, que exige futuro, retomada, signos a vir. Isso significa que a nova estrutura, configuração ou desenho, não é determinada por algo em si, cuja lei ou sintaxe estariam disponíveis, mas pela modificação de um fundo que não é percebido e que, por sua vez, modifica a figura. Em outras palavras, o que não está dito, nem é perceptível, comanda a estrutura. Tal é a "teoria da consciência inversa: por definição a consciência deforma (louche): o fato de termos consciência disto quer dizer também que há aquilo de não-dito. E no entanto ela não está cortada do verdadeiro, já que o que ela não diz está presente como fundo: teleologia da verdade" (pg. 51, lição 1). A verdade é teleológica porque não diz respeito ao que é dito ou enunciado em sentido apofântico, mas pressentido por uma consciência que desloca a linguagem em direção ao porvir.

Se olharmos para 0 Visivel e invisivel e 0 olho e o espírito, o princípio dos anos 50 funcionam como preparação para os temas futuros, como a carne, o quiasma e a Natureza ${ }^{1}$. Numa das folha avulsas anexas à lição 1 de 0 Mundo sensivel e o mundo da expressão, Merleau-Ponty diz: “Passagem à expressão criadora, à produtividade. Mas isso não é por hora senão a introdução ao mundo da expressão, isto é, primeiro exemplo de uma atividade expressiva que será, em seguida, o espírito" (p. 52, lição 1). Reencontramos aqui a dupla finalidade do curso, que é prolongar a fenomenologia da percepção a partir de uma teoria da expressão, fazendo uma teoria concreta do espírito. Tudo se passa como se o conceito de expressão prefigurasse a base material para os textos estéticos, para a psicanálise da Natureza e para a ontologia do sensivel. Que se lembre o conceito de "Instituição" como produtividade humana (retomado, na década de 60, sob o nome de "Erzeugung"), tema de curso do ano seguinte, 1954-1955, no Collège de France ${ }^{2}$. Tal relação de continuidade não descarta a crítica e a reformulação do projeto inicial do filósofo, à luz de novos temas em curso (como a passividade, a instituição e a expressão). A conclusão que podemos tirar é que, contrapondo o projeto inicial da Fenomenologia com 0 visivel e o invisível, 0 Mundo sensivel e o mundo da expressão e os cursos imediatamente sucessivos sinalizam, ao mesmo tempo, a continuidade e a evolução do pensamento do filósofo.

Com efeito, ao longo do texto, há constantes retomadas de questões originalmente formuladas nas duas primeiras obras do filósofo, agora consideradas à luz da temática da expressão, como se as novas análises tivessem um efeito retroativo sobre os resultados obtidos anteriormente (na Estrutura do comportamento e na Fenomenologia da percepção). Assim, por exemplo, no contexto da Fenomenologia, dizer que toda e qualquer percepção é, necessariamente, percepção-de-figura-sobre-fundo consiste, num só gesto, tanto em 
desmistificar o cânone objetivista das explicações empírico-causais quanto em ampliar o arsenal teórico da ciência, haja vista que esta última trabalha com oposições categoriais demasiadamente rígidas para lidar com a ambiguidade essencial do percebido com a qual se depara frequentemente (e.g., como definir objetivamente os limites do campo visual?). Merleau-Ponty endossa e eleva o valor filosófico da aposta da Gestaltheorie em um novo princípio de inteligibilidade, ao procurar elaborar uma filosofia da forma que permite compreender a ambigüidade. Trata-se, em suma, de caracterizar fenomenologicamente 0 sentido positivo das zonas de indeterminação sem as quais não pode haver determinação alguma. Trata-se do fundo tácito, dinâmico e fundante, sem o qual não pode haver figura, enquanto entidade percebida. No curso de 53, por sua vez, quando já podemos vislumbrar claramente os primeiros contornos do problema da "origem da verdade" (p. 64), ao qual Merleau-Ponty se volta inteiramente em 0 visível e o invisível, há uma espécie de radicalização dos resultados obtidos nos dois primeiros trabalhos do filósofo. Como se a pergunta pelo ser da forma, - explicitamente formulada, mas respondida de maneira pouco satisfatória nas primeiras obras - tomasse um novo fôlego, acabando por conduzir a investigação inicial a uma nova dimensão, que exige o "abandono da noção de consciência" (p. 51). Tanto que a análise merleau-pontyana do fenômeno do "espaço e movimento" (p. 70) dará prioridade, como bem aponta Saint Aubert, menos àquilo sem o que... (conforme a definição clássica de essência, frequentemente associada à análise reflexiva, que se trata de superar) do que àquilo pelo que... ou seja, interessa, agora, e cada vez mais a Merleau-Ponty, apreender o "sentido positivo" do "movimento nascente" (p. 70), a realidade do movimento em vias de ser.

Precisemos, no curso de 1953, uma passagem crítica em relação ao projeto da Fenomenologia. Lemos na terceira lição, sobre o bojo da página, o título: “Elaboração de uma teoria da racionalidade". A nova teoria que aparece é a passagem da consciência perceptiva para a expressão, isto é, sublimação, virtualidade, dos bens culturais sobre o plano do indivíduo, de um lado, e emergência do plano simbólico sobre o orgânico, de outro. Como aponta Merleau-Ponty, "a expressão cultural ultrapassa a expressão natural. Somos tentados a fazer intervir aqui o espírito. Darstellungsfunktion, symbolic thinking, etc. Todavia, como é um tudo ou nada, isso seria retorno à filosofia da consciência. (...) Aos olhos do próprio mundo cultural (e não somente do mundo natural), considerar a práxis como constituinte. Nossa consciência perceptiva, consciência invertida, que deixa aparecer ou desvelar um percebido sem o possuir, é já uma atividade de freqüentação, uma familiaridade com... uma práxis mais do que uma gnôsis" (p. 65, lição 3). A superioridade da práxis sobre a gnôsis exige uma consciência ambígua e anônima, isto é, consciência projetiva, lateral e sub-reptícia que, ao contrário da consciência moderna, não compreende os obje- 
tos senão de modo tácito e presuntivo, invertendo a figura e o fundo. 0 conhecimento é um ato do espírito, ao passo que a práxis é virtual ou possível. Ela é movimento para, ação projetiva, concentração do espírito. Em outras palavras: "consciência ambígua = há outro ponto de vista do que este que vemos, que coloca em figura o que colocamos no fundo" (p. 65, lição 3). Essa crítica à noção de consciência alcança, em última análise, o próprio conceito de intencionalidade de $\mathrm{Husserl}^{3}$, uma vez que a expressão, no contexto do curso de 1953, reduz a percepção ao "silêncio". “Percepção = ‘mutismo'. Pois que não contato com um ob-jecto. Modulação de um fundo sem o qual não há figura. Ora, o fundo 'vai por si' (selbstverstänflich), não é posto. É nível, isto é, não-perceptível. De onde consciência perceptiva $=$ indireta (pelo fundo) e invertida (enquanto que não explicita seu fundo). $E$ aqui se vê vinculado consciência de coisa e consciência expressiva" (p. 60, lição 3). Expressividade, em suma, é a negatividade da consciência que vive a maior parte do tempo em silêncio, freqüentando o mundo.

Mas essa é a razão para a mudança em relação ao projeto da Fenomenologia, que a expressão leva a campo. 0 texto de $A$ prosa do mundo, escrito nesse mesmo período, já dizia que "a percepção estiliza" 4 , isto é, que ao mundo natural do espírito corresponde um desdobramento lingüístico, sem o qual aquele seria vazio e incompleto. Ao analisar o conceito de espaço, na quarta lição, Merleau-Ponty diz: “A existência espacial não é lógica. (...) Portanto, especialidade intuitiva. (...) Espaço relacional. 0 aqui, o lá, 0 onde, não têm outro sentido senão como cortes da totalidade. 0 espaço não é feito de partes" (p. 75, lição 4). Tal é, segundo Merleau-Ponty, a vitória de Bergson sobre Zenão: o movimento no espaço, para ser reconstituído em leis internas, supõe a experiência vivida, que o pensamento lógico oblitera. Razão pela qual “é preciso opor o espaço aos nossos enunciados sobre o espaço, restituir o espaço além deles, considerar o positivismo lógico como pensamento criteriológico que define não nosso acesso ao verdadeiro, mas as condições para evitar o erro; não a especialidade efetiva, mas seu balizamento lógico" (p. 74, lição 4). Pensar corretamente não significa mais, nessa crítica à lógica transcendental, estar livre do erro, assegurando, de antemão, 0 verdadeiro, mas a errância, a tentativa e a disposição de um enunciado heurístico que, mais do que dizer claramente, pratica a ambigüidade do mundo.

A insistência sobre o "polimorfismo da consciência, ambivalência, consciência indireta ou invertida", segundo as palavras de Merleau-Ponty, "colocam o problema de compreender como uma retomada deste polimorfismo é possível de modo a que transforme o equívoco em significação, a ambivalência em ambigüidade" (p. 174, notas anexas ${ }^{5}$ ). 0 processo que transforma o equívoco em significação, a contradição em ambigüidade produtiva, pode ser encontrado na unidade práxica (mas também gnóstica) do esquema corporal. “0 esque- 
ma corporal e o corpo estão situados não onde estão objetivamente, mas onde estamos dispostos a colocá-los. Resulta disso que o esquema corporal é sempre orientado sobre posições privilegiadas, normas, e a consciência que temos é, sobretudo, a de um desvio em relação a estas normas" (p. 139, lição 11).

Para concluir, vale a pena citar e comentar brevemente uma pequena passagem do primeiro curso, sobre o "problema da consciência perceptiva", onde podemos assistir ao encontro de dois temas caríssimos a Merleau-Ponty (a saber, percepção e linguagem), patrocinado pela noção de expressão: “0 paradoxo, aqui [em relação à consciência perceptiva], é o mesmo dos signos: os signos são diacríticos, i.e., cada um marca uma diferença de significação, não uma significação; e a linguagem acaba por significar à força de marcar diferenças de significação, sem com isso jamais trazer alguma que seja positiva" (p. 178). Será preciso elaborar, portanto, uma "concepção diacrítica do signo perceptivo" (p. 203), onde consciência seja "sinônimo de impercepção" (p. 204). Eis, aqui, um passo decisivo de Merleau-Ponty no sentido de se afastar definitivamente da teoria husserliana da doação por esboços, conforme o modelo da intencionalidade de horizontes anteriormente adotado: assim como cada palavra pronunciada traz consigo uma certa modulação de silêncio, cada gesto perceptivo, cada perspectiva sob a qual a coisa se apresenta, implica uma certa zona de invisibilidade, lacunas, "impercepção" inerente ao ser das coisas.

As notas que compõem 0 mundo sensivel e o mundo da expressão são riquíssimas na variedade de temas, na densidade dos conceitos e na complexidade das questões com as quais trabalha, convidando o leitor ao diálogo e à interpretação. Num contexto mais apropriado, seria interessante confrontar sistematicamente tal abordagem àquela que predominava nas primeiras obras de Merleau-Ponty, quando, a despeito do tom quase sempre crítico para com o idealismo transcendental, transparecia fortemente o apreço do filósofo francês por noções como "fundação" (Fundierung), "si" etc., de inspiração nitidamente fenomenológica.

1 Como lembra Étienne Bimbenet, Merleau-Ponty opera um conceito de Natureza que não é contraditório ao conceito de espírito, e vice-versa. Cf. Nature et humanité. Paris:Vrin, 2004.

2 MERLEAU-PONTY, Maurice. L'instituition, la passivité - Notes de cours au Collège de France (1954-1955). Paris: Éditions Belin, 2003.

3 Razão para Merleau-Ponty insistir na leitura da "fungierende Intentionalität" (intencionalidade operante), intencionalidade sem atos, unidade antrepredicativa, anônima e oculta entre o mundo e a vida, encontrada na Krisis e nas Ideen II de Edmund Husserl.

4 MERLEAU-PONTY. Maurice. A prosa do mundo. São Paulo: Cosac \& Naify, 2002, p.86.

5 Trata-se de folhas avulsas, organizadas pelos editores, de modo temático, ao final do livro. 